\title{
An Evaluation of the Effects of Betahistine and Dimenhydrinate on Posterior Canal Benign Paroxysmal Positional Vertigo
}

\author{
Original Investigation \\ Hakkı Caner İnan (1), Merve Kıraç (D) \\ Department of Otorhinolaryngology, Erzincan University School of Medicine, Erzincan, Turkey
}

Abstract

ORCID IDs of the authors: H.C.I. 0000-0001-6254-372X; M.K. 0000-0002-7710-441X.

Cite this article as: Inan HC, Kıraç M. An Evaluation of the Effects of Betahistine and Dimenhydrinate on Posterior Canal Benign Paroxysmal Positional Vertigo. Turk Arch Otorhinolaryngol 2019; 57(4): 191-6.

\section{Corresponding Author:}

Hakkı Caner Inan; hakkicanerinan@gmail.com

Received Date: 13.02 .2019

Accepted Date: 26.09.2019

Content of this journal is licensed under a Creative Commons Attribution 4.0 International License. Available online at www.turkarchotolaryngol.net
Objective: Benign paroxysmal positional vertigo (BPPV) is the most common peripheral vestibular system disease causing dizziness. It occurs more in the 5 th decade of life and affects the posterior canal in $90 \%$ of the patients. The most effective treatment method is canalith repositioning (CRP) maneuver. The aim of this study is to evaluate the effects of betahistine and dimenhydrinate therapies in addition to CRP maneuver on BPPV patients.

Methods: The study included 64 patients who had complaints of dizziness and were diagnosed with BPPV by their history and provocation maneuvers. The patients were divided into two groups. In Group 1, only repositioning maneuver was performed. Group 2 was divided into two subgroups. In Group 2a, repositioning maneuver was performed and betahistine $24 \mathrm{mg}$ twice daily was given for 10 days. In Group 2b, repositioning maneuver was performed and dimenhydrinate 50 $\mathrm{mg}$ once daily was given for five days. On the $10^{\text {th }}$ day, all patients were reexamined, and provocation maneuver was performed. Dizziness handicap inventory (DHI) was completed and outcomes were reviewed for therapeutic efficacy.

Results: Mean DHI scores in all patient groups statistically significantly decreased from a pre-treatment level of 52.16 (range, 20-100) to a post-treatment level of 17.84 (range, 0-78) $(p<0.001)$. No statistically significant differences were found in terms of DHI scores between Group 1 (repositioning maneuver only) and Group 2 (repositioning maneuver plus betahistine or dimenhydrinate).

Conclusion: The most effective treatment method of BPPV is repositioning maneuver. Addition of betahistine or dimenhydrinate pharmacotherapy to repositioning maneuver did not show superiority to treatment with repositioning maneuvers alone.

Keywords: Benign paroxysmal positional vertigo, canalith repositioning maneuver, pharmacotherapy, Epley maneuver

\section{Introduction}

Benign paroxysmal positional vertigo (BPPV), seen in $19 \%$ of patients who present with complaints of dizziness, is the most common vestibular system disorder that causes peripheral vertigo (1). Its prevalence is reported between 10.7 and 64 in 100,000 (2,3). It generally emerges in the $5^{\text {th }}$ decade of life. While it is mostly seen unilaterally with single canal involvement, more than one semicircular canal may be occasionally affected. Patients present with complaints of sudden episodes of dizziness especially with the movement of the head (4). Despite recovery with spontaneous remission of the disease in days or weeks, recurrence may develop in $50 \%$ of the patients (5).

According to the canalolithiasis theory, which has been suggested in the formation of the disease, otoconia in the utricle break and fall into the semicircular canal, then swimming in the endolymphatic fluid, inappropriately stimulate the vestibular nerve as the head is moved. According to another theory, (6) otoconia ad- 
here to the cupula of the semicircular canals and become more sensitive with the influence of gravity on the cupula (cupulolithiasis). Although most cases are idiopathic, head trauma, metabolic diseases and hormonal disorders may cause BPPV (7).

The most common type of BPPV is posterior canal BPPV, seen in $90 \%$ of the cases. This is followed by horizontal canal BPPV at a rate of $5-15 \%$ (2). The most accepted treatment method for the disease is canalith repositioning procedures (CRPs). The aim of canalith repositioning maneuver is to send the otoconia back to the utricle through mobilization with correct head movements (8). Other methods that can be used in treatment are vestibular exercises, sedative drugs effective on the labyrinth, drugs such as betahistine that are thought to increase vestibular blood flow, and surgery in resistant cases.

Vestibular disorders have a negative effect on patients' quality of life, and ultimately cause workforce loss. Eliminating the disease with the most appropriate methods significantly increases the quality of life.

The aim of this study was to investigate the effects of a medical treatment of betahistine or dimenhydrinate administered together with canalith repositioning maneuvers-the most significant treatment method-in patients with BPPV.

\section{Methods}

Approval for the study was granted by the Ethics Committee of Erzincan Binali Yıldırım University (Aug 27, 2018-33216249604.01.01-E.36300). All patients enrolled in the study were informed about the purpose of the study and provided their written informed consent. The study included 64 patients who presented with dizziness and were diagnosed with BPPV by the Dix-Hallpike maneuver. Patients with a cervical spine disease in whom provocation tests could not be performed, and those with carotid artery stenosis, Meniere's disease, central vertigo or previous ear surgery were excluded from the study. The canalith repositioning maneuver was performed in all the patients included in the study.
Epley's maneuver was applied to patients with posterior canal BPPV. Dix-Hallpike and Epley maneuvers were performed in the initial diagnosis and treatment session and by the same doctor and audiologist who has authored this paper. The patients were divided into two groups according to their medical records. Only the repositioning maneuver was performed in Group 1. Group 2 was divided into two subgroups. In Group 2a, in addition to the repositioning procedure, patients received betahistine $\left(\right.$ Betaserc $^{\circledR}$, Abbott Healthcare SAS, Châtillon-sur-Chalaronne, France) $24 \mathrm{mg}$ twice daily for 10 days. In Group 2b, in addition to the repositioning maneuver, patients received dimenhydrinate (Dramamine, Ali Raif İlaç, İstanbul, Turkey) $50 \mathrm{mg}$ once a day for five days. On the $10^{\text {th }}$ day, all patients were reexamined, and the provocation maneuver was repeated to investigate the presence of vertigo. The dizziness handicap inventory (DHI) was filled-out both at the time of diagnosis and on the $10^{\text {th }}$ day of the treatment. DHI was filled-out by the same audiologist by interviewing the patients in Turkish language. The inventory comprised of 25 questions and the response options were 'yes' (4 points), 'sometimes' ( 2 points) and 'no' (0 points). Patients' responses were then scored, and results were evaluated. The DHI was used to allow for more objective criteria in the evaluation of dizziness and its influence on patients' quality of life.

\section{Statistical Analysis}

Statistical analysis was performed using the Statistical Package for the Social Sciences version 15.0 software (SPSS Inc., Chicago, IL, USA). Descriptive data were expressed in arithmetic mean and standard deviation (SD), and median (min-max) values. Numerically obtained data were expressed in percentile (\%). Paired T test was used for comparing pre- and post-treatment DHI scores between the groups. Abnormally distributed data among the three (sub)groups were analyzed using the Kruskal-Wallis variance analysis. A p-value of $<0.05$ was considered statistically significant.

\section{Results}

Posterior canal BPPV was identified in all 64 patients aged 18 to 80 years (mean age: 53.70 years); 34 (53.12\%) were male

Table 1. Comparison of groups by gender and age

\begin{tabular}{|c|c|c|c|c|c|c|c|}
\hline & \multicolumn{6}{|c|}{ Treatment type } & \multirow[b]{3}{*}{$\mathrm{p} \Phi$} \\
\hline & \multicolumn{2}{|c|}{ Repositioning Maneuver ( $n=24)$} & \multicolumn{2}{|c|}{$\mathrm{RM}+$ Betahistine $(\mathrm{n}=24)$} & \multicolumn{2}{|c|}{ RM+Dimenhydrinate $(\mathrm{n}=16)$} & \\
\hline & Number & $\% *$ & Number & $\% *$ & Number & $\% *$ & \\
\hline \multicolumn{8}{|l|}{ Gender } \\
\hline Male & 13 & 54.2 & 10 & 41.7 & 7 & 43.8 & 0.658 \\
\hline Female & 11 & 45.8 & 14 & 58.3 & 9 & 56.3 & \\
\hline \multicolumn{8}{|c|}{ Age (Years) } \\
\hline$\leq 50$ & 9 & 37.5 & 10 & 41.7 & 6 & 37.5 & 0.947 \\
\hline$>51$ & 15 & 62.5 & 14 & 58.3 & 10 & 62.5 & \\
\hline
\end{tabular}

*Column percentage p $\mathbf{q}$ : Pearson's Chi-square test was used 
Table 2. Comparison of pre- and post-treatment DHI scores by treatment methods

\begin{tabular}{l|c|c|c|c|c|}
\hline \multirow{2}{*}{ Maneuver only } & \multicolumn{2}{|c|}{ Pre-treatment DHI } & \multicolumn{2}{|c}{ Post-treatment DHI } \\
\cline { 2 - 5 } & Mean \pm SD & Median (Min-Max) & Mean \pm SD & Median (Min-Max) & $\mathrm{p}^{*}$ \\
\hline$(\mathrm{n}=24)$ & $47.25 \pm 21.47$ & 49.00 & $15.83 \pm 19.87$ & 10.00 \\
\hline Maneuver + Medical treatment & $56.00 \pm 20.81$ & $(20-88)$ & $(0.0-78.0)$ & $<0.001$ \\
\hline$(\mathrm{n}=40)$ & & 55.00 & $18.55 \pm 14.00$ & 16.89 \\
\hline
\end{tabular}

SD: standard deviation *Paired $\mathrm{T}$ test was used

Table 3. Comparison of pre- and post-treatment DHI scores by treatment methods

\begin{tabular}{l|c|c|c|c|c}
\hline \multirow{2}{*}{} & \multicolumn{2}{|c|}{ DHI Pre-treatment } & \multicolumn{2}{|c|}{ DHI Post-treatment } \\
\cline { 2 - 5 } & Mean \pm SD & Median (Min-Max) & Mean \pm SD & Median (Min-Max) & $\mathrm{p}^{*}$ \\
\hline Betahistine & $53.33 \pm 21.59$ & 51.00 & $18.16 \pm 16.59$ & 14.00 \\
\hline$(\mathrm{n}=24)$ & & $(22.0-94.0)$ & & $(0.0-64.0)$ \\
\hline Dimenhydrinate & $60.00 \pm 19.56$ & 56.0 & $19.62 \pm 17.43$ & 16.00 \\
\hline$(\mathrm{n}=16)$ & & $(26.0-100.0)$ & & $<0.001$ \\
\hline
\end{tabular}

SD: standard deviation *Paired $\mathrm{T}$ test was used

Table 4. Comparison of percentile decrease in DHI scores by type of treatment

\begin{tabular}{|c|c|c|c|c|}
\hline & \multicolumn{3}{|c|}{ Treatment Type } & \multirow[b]{3}{*}{$\mathrm{p}^{*}$} \\
\hline & $\begin{array}{c}\text { Repositioning } \\
\text { Maneuver } \\
(n=24)\end{array}$ & $\begin{array}{c}\text { RM+ } \\
\text { Betahistine } \\
(n=24)\end{array}$ & $\begin{array}{c}\mathrm{RM}_{+} \\
\text {Dimenhydrinate } \\
(\mathrm{n}=16)\end{array}$ & \\
\hline & Mean \pm SD & Mean \pm SD & Mean \pm SD & \\
\hline $\begin{array}{l}\text { Percentile } \\
\text { decrease } \\
\text { in DHI score }\end{array}$ & $69.45 \pm 28.30$ & $70.83 \pm 22.36$ & $70.52 \pm 20.47$ & 0.971 \\
\hline
\end{tabular}

and $30(46.88 \%)$ were female. The right-side canal was affected in 38 (59\%) patients and the left-side canal in 26 (41\%). Two patients had recently suffered a head trauma, one patient had been in a traffic accident, and one had recently undergone surgery.

Group 1 (repositioning maneuver only) consisted of 24 (37.5\%) patients. Group 2a (repositioning maneuver plus betahistine) consisted of 24 (37.5\%) patients, and Group $2 \mathrm{~b}$ (repositioning maneuver plus dimenhydrinate) consisted of $16(25 \%)$ patients. In the follow-up examination on the $10^{\text {th }}$ day, the provocation maneuver provoked vertigo in two patients-one from Group 1, and one from Group 2b. Patients were analyzed as two groups based on age: $\leq 50$ years and $>50$ years. There were no significant differences in terms of treatment types, gender or age $(\mathrm{p}=0.658$ and $\mathrm{p}=0.947$, respectively) (Table 1).

The mean DHI score of the three patient (sub)groups statistically significantly decreased from a pre-treatment level of 52.16 (range, 20-100) to a post-treatment level of 17.84 (range, 0-78) $(\mathrm{p}<0.001)$.

Mean DHI scores in Group 1 (repositioning maneuver only), was 47.75 before the treatment and 15.83 after the treatment. This difference between pre- and post-treatment scores was found statistically significant $(p<0.01)$. Mean DHI scores in both subgroups of Group 2 (pharmacotherapy after repositioning maneuver) were 56.00 before the treatment and 18.55 after the treatment, and this difference was also found statistically significant $(\mathrm{p}<0.001)$ (Table 2).

In Group 2a (repositioning maneuver plus betahistine) mean DHI score was 53.33 before the treatment and 17.83 after the treatment. In Group 2b (repositioning maneuver plus dimenhydrinate) mean DHI score was 60 before the treatment and 19.62 after the treatment. In both groups, post-treatment DHI values were statistically significantly lower than pre -treatment values $(\mathrm{p}<0.001)$ (Table 3$)$.

When the change in DHI scores from pre- to post-treatment were analyzed, a mean decrease of $69.45 \%$ was found in Group 1, of $70.83 \%$ in Group 2a, and of $70.52 \%$ in Group 2b. No statistically significant differences were found in percentage decreases with respect to the type of treatment $(\mathrm{p}=0.971)$ (Table 4).

\section{Discussion}

BPPV is characterized by sudden episodes of dizziness which occur with the movement of the head. The disease more commonly emerges in older ages and its etiology is unclear. It has been shown that some age-related degenerative changes may have a role in its pathophysiology. Thalmann et al. (9) reported 
that deterioration in the elasticity and adhesivity of the subunits in the macula matrix, where otoconia are located, is responsible for the disease. A significant correlation with utricular dysfunction has been identified in patients aged $>65$ years with ocular $\operatorname{VEMP~(10).~}$

In a study of $101 \mathrm{BPPV}$ patients by Silva et al. (11) the mean age was found 56.57 years (range, 15-90 years). The posterior canal was affected in $72.3 \%$, the lateral canal in $24.7 \%$, the anterior canal in $2 \%$, and multiple canals were affected in $1 \%$ of the patients. In regard of etiology, $83.2 \%$ of the cases were idiopathic. Repositioning maneuver was reported to be effective in $90 \%$ of the patients. Likewise, in our study, most of the patients were in their $5^{\text {th }}$ decade of life, their posterior canal was most affected, and majority of the cases were idiopathic.

The DHI was first developed by Jacobson and Newman (12) in 1990. The inventory consists of 25 questions that address sensory and functional outcomes in vestibular system diseases as well as the factors that aggravate patients' dizziness and balance disorder. Questions 1, 4, 8, 11, 13, 17 and 25 measure physical disability; questions $2,9,10,15,18,20,21$, 22 and 23 measure emotional disability. Questions 3, 5, 6, $7,12,14,16,19$ and 24 are structured to measure functional disability. Response options are, 'yes' (4 points), 'no' (0 points) and 'sometimes' (2 points). Dizziness is seen to have a significantly negative effect on patients' lives in patients with high scores. The Turkish validity and reliability study of the inventory was conducted by Canbal et al. (13) in 2015. The findings of this study showed that the inventory could be used in patients with dizziness in our country and has sufficient validity and reliability coefficients. The study concludes that using this inventory would help to monitor complaints of dizziness and its effects on patients' quality of life with more objective criteria (13).

Vestibular rehabilitation exercises, medical treatment, and surgery in resistant cases, are the methods that can be applied in its treatment (14). The most effective method in the management of BPPV is the correct and careful application of repositioning maneuvers. In most patients, a positive Dix-Hallpike test reveals the condition and the severity of vertigo decreases with a single repositioning maneuver (15). In a study of 21 patients with posterior BPPV, the effects of the Epley maneuver on the physical, functional and emotional states of patients were evaluated using the DHI. Mean follow-up period was 21 days. Physical, functional and emotional DHI scores (pre-treatment: 17.5, 17.3 and 13.2, respectively) significantly decreased following the treatment to 3.7, 3.9 and 3.2, respectively (16). In our study, post-treatment DHI scores were found significantly lower in Group 1 (repositioning maneuver only) compared to the pre-treatment scores, and this was seen to be consistent with the literature. In the follow-up examination on the 10 day, recurrence was identified in 2 out of 64 patients.
Agents such as betahistine and dimenhydrinate can be used in the medical treatment of BPPV (17). Betahistine is an analog of histamine and is used in Meniere's disease and $\mathrm{BPPV}$. Betahistine increases microcirculation in the inner ear by creating vasodilatation. This mechanism is reported to be effective in recurrent BPPV by increasing vestibular compensation. A review, which investigated the effects of the use of betahistine in peripheral vertigo treatment, reported that the safety and the efficacy of betahistine has been shown in several studies (18). Betahistine is used in clinical practice for 40 years, with treatment doses of 8 to $48 \mathrm{mg} /$ day, and no safety problems have been reported. According to the studies examined in the referred review, the use of betahistine 48 $\mathrm{mg} /$ day for 3 months is an effective and safe method in the treatment of peripheral vertigo (18). In our study, Group $2 \mathrm{a}$ was given betahistine $48 \mathrm{mg} /$ day for 10 days after the repositioning maneuver. No safety problems were encountered in any of the patients.

In a study by Maslovara et al. (19), $96 \mathrm{BPPV}$ patients were divided into two groups; Group 1 received betahistine chloride, and Group 2 received only rehabilitation treatment. Provocation maneuver and DHI were used for follow-up. The patients were evaluated in the $1^{\text {st }}$ and $8^{\text {th }}$ weeks of the treatment. In the first follow-up examination, Dix-Hallpike test was negative in $86.96 \%$ of Group 1, and in $93.3 \%$ of Group 2. In the $8^{\text {th }}$ week these rates were $95.65 \%$ and $97.78 \%$, respectively. A greater and more rapid recovery was observed in Group 2.

In another study, which evaluated betahistine treatment, $90 \mathrm{pa}^{-}$ tients diagnosed with BPPV were examined with the Dix-Hallpike test. In group A, they treated patients with only Epley maneuver; in group B they used maneuver plus betahistine; in group $\mathrm{C}$ they used betahistine alone. A better response to treatment was seen and fewer relapses and recurrences were observed in the patient group treated with Epley maneuver plus betahistine (20). Review of studies comparing Epley maneuver with medical treatment showed comparable recovery in both groups, and betahistine was reported to shorten the recovery period. It has also been reported that betahistine could be effective on residual symptoms, such as anxiety, panic and insomnia in BPPV patients (21).

In our study, DHI and provocation maneuver were performed on the $1^{\text {st }}$ and $10^{\text {th }}$ days to compare the treatments. No superiority was observed over the Epley maneuver alone by adding betahistine to the treatment. This result could be expected since repositioning maneuver is the fundamental effective treatment in BPPV. All patients in the presented study were first treated with the repositioning maneuver.

A study, which investigated the safety and efficacy of $40 \mathrm{mg}$ dimenhydrinate in 1,275 vertigo patients, showed this treatment to be an effective and well-tolerated method in the treatment of vertigo. There are, however, few studies that show the efficacy of 
dimenhydrinate treatment in BPPV (17). In a study by Kim et al. (22) vestibular suppressants were shown to alleviate residual symptoms in BPPV patients. In this study of 150 idiopathic BPPV patients, canalith repositioning maneuver was performed in the initial examination and DHI was used. The patients were divided into three groups; one group received dimenhydrinate, one group received the placebo, and one group received no medical treatment. When DHI scores were examined, there was no significant decrease in the dimenhydrinate group, and the scores of the three groups were found comparable.

The limited number of patients and short follow up time (10 days) were the primary limitations of our study. Further studies with larger numbers of patients are needed to further explore the efficacy of medical treatments in BPPV. Another limitation of our study is that there was not a control group using placebo.

\section{Conclusion}

According to the results of our study, the repositioning maneuver is the most effective treatment in BPPV patients. Betahistine or dimenhydrinate treatment started in the early period following the repositioning maneuver showed no superiority when the DHI scores were examined. Considering that the majority of BPPV patients are aged over 50 years and could be using multiple drugs, prescribing a medical treatment may not be suitable once the repositioning maneuver is correctly and carefully applied.

Ethics Committee Approval: Ethics committee approval was received for this study from the Ethics Committee of Erzincan Binali Y1ldırım University (Aug 27, 2018-33216249-604.01.01-E.36300).

Informed Consent: Written informed consent was obtained from the patients who participated in this study.

Peer-review: Externally peer-reviewed.

Author Contributions: Concept - H.C.İ, M.K.; Design - H.C.İ, M.K.; Supervision - H.C.İ; Data Collection and/or Processing H.C.İ, M.K.; Analysis and/or Interpretation - H.C.İ, M.K.; Literature Search - H.C.İ, M.K.; Writing - H.C.İ; Critical Reviews - H.C.İ, M.K.

Conflict of Interest: The authors have no conflicts of interest to declare.

Financial Disclosure: The authors declared that this study has received no financial support.

\section{References}

1. Bhattacharyya N, Baugh RF, Orvidas L, Barrs D, Bronston LJ, Cass S, et al. Clinical practice guideline: benign paroxysmal positional vertigo. Otolaryngol Head Neck Surg 2008; 139: S47-81. [CrossRef]

2. Bhattacharyya N, Gubbels SP, Schwartz SR, Edlow JA, El-Kashlan H, Fife T, et al. Clinical practice guideline: benign paroxysmal positional vertigo (update). Otolaryngol Head Neck Surg 2017; 156: S1-S47. [CrossRef]

3. Froehling DA, Silverstein MD, Mohr DN, Beatty CW, Offord $\mathrm{KP}$, Ballard DJ. Benign positional vertigo: incidence and prognosis in a population-based study in Olmsted County, Minnesota. Mayo Clin Proc 1991; 66: 596-601. [CrossRef]

4. Zaag-Loonen HV, Bruintjes T, Leeuwen RV. Probable benign paroxysmal positional vertigo converts into definite BPPV in one in six Patients. J Int Adv Otol 2018; 14: 456-8. [CrossRef]

5. Ciorba A, Cogliandolo C, Bianchini C, Aimoni C, Pelucchi S, Skarżyński $\mathrm{PH}$, et al. Clinical features of benign paroxysmal positional vertigo of the posterior semicircular canal. SAGE Open Med 2019; 7: 1-5. [CrossRef]

6. Parnes LS, McClure JA. Free-floating endolymph particles: a new operative finding during posterior semicircular canal occlusion. Laryngoscope 2015; 125: 1033-7. [CrossRef]

7. Luryi AL, LaRouere M, Babu S, Bojrab DI, Zappia J, Sargent EW, et al. Traumatic versus idiopathic benign positional vertigo: analysis of disease, treatment, and outcome characteristics. Otolaryngol Head Neck Surg 2018; 160: 131-6. [CrossRef]

8. Kim JS, Zee DS. Benign paroxysmal positional vertigo. N Engl J Med 2014; 370: 1138-47. [CrossRef]

9. Thalmann R, Ignatova E, Kachar B, Ornitz DM, Thalmann I. Development and maintenance of otoconia: biochemical considerations. Ann N Y Acad Sci 2001; 942: 162-78. [CrossRef]

10. Fujimoto C, Kawahara T, Kinoshita M, Kikkawa YS, Sugasawa $\mathrm{K}$, Yagi $\mathrm{M}$, et al. Aging is a risk factor for utricular dysfunction in idiopathic benign paroxysmal positional vertigo. Front Neurol 2018; 9: 1049. [CrossRef]

11. Silva C, Amorim AM, Paiva A. Benign paroxysmal positional vertigo: a review of 101 cases. Acta Otorrinolaringol Esp 2015; 66: 205-9. [CrossRef]

12. Jacobson GP, Newman CW. The development of the dizziness handicap inventory. Arch Otolaryngol Head Neck Surg 1990; 116: 424-7. [CrossRef]

13. Canbal M, Cebeci S, Duyan GÇ, Kurtaran H, Arslan İ. A study of reliability and validity for the Turkish version of dizziness handicap inventory. J Family Med Prim Care 2016; 10: 19-24. [CrossRef]

14. Imai $T$, Takeda $N$, Ikezono $T$, Shigeno $K$, Asai M, Watanabe $\mathrm{Y}$, et al. Classification, diagnostic criteria and management of benign paroxysmal positional vertigo. Auris Nasus Larynx 2017; 44: 1-6. [CrossRef]

15. Ballvé JL, Carrillo-Muñoz R, Rando-Matos Y, Villar I, Cunillera $\mathrm{O}$, Almeda J, et al. Effectiveness of the Epley manoeuvre in posterior canal benign paroxysmal positional vertigo: a randomised clinical trial in primary care. Br J Gen Pract 2019; 69: e52-e60. [CrossRef]

16. Pereira AB, Santos JN, Volpe FM. Effect of Epley's maneuver on the quality of life of paroxysmal positional benign vertigo patients. Braz J Otorhinolaryngol 2010; 76: 704-8. [CrossRef]

17. Scholtz AW, Ilgner J, Loader B, Pritschow BW, Weisshaar G. Cinnarizine and dimenhydrinate in the treatment of vertigo in medical practice. Wien Klin Wochenschr 2016; 128: 341-7. [CrossRef]

18. Ramos Alcocer R, Ledezma Rodríguez JG, Navas Romero A, Cardenas Nuñez JL, Rodríguez Montoya V, Deschamps JJ, et al. Use of betahistine in the treatment of peripheral vertigo. Acta Otolaryngol 2015; 135: 1205-11. [CrossRef] 
19. Maslovara S, Soldo SB, Puksec M, Balaban B, Penavic IP. Benign paroxysmal positional vertigo (BPPV): influence of pharmacotherapy and rehabilitation therapy on patients' recovery rate and life quality. NeuroRehabilitation 2012; 31: 435-41. [CrossRef]

20. Kaur J, Shamanna K. Management of benign paroxysmal positional vertigo: a comparative study between Epleys manouvre and Betahistine. Int Tinnitus J 2017; 21: 30-4. [CrossRef]
21. Wan TJ, Yu YC, Zhao XG, Tang P, Gong YS. Efficacy of betahistine plus cognitive behavioral therapy on residual dizziness after successful canalith repositioning procedure for benign paroxysmal positional vertigo. Neuropsychiatr Dis Treat 2018; 14: 2965-71. [CrossRef]

22. Kim M-B, Lee HS, Ban JH. Vestibular suppressants after canalith repositioning in benign paroxysmal positional vertigo. Laryngoscope 2014; 124: 2400-3. [CrossRef] 